Padjadjaran Nursing Journal (Jurnal Keperawatan Padjadjaran)

ISSN 2338-5324 (print)

ISSN 2442-7276 (online)

Online di http://jkp.fkep.unpad.ac.id

DOI : $10.24198 / \mathrm{jkp}$

\title{
Factors Associated with Death Anxiety in Elderly Batak Tribe who Live in Bandung
}

\author{
Mamat Lukman', Ferdinan Sihombing ${ }^{2}$, Lia Meilianingsih ${ }^{3}$ \\ ${ }^{1}$ Faculty of Nursing Universitas Padjadjaran, ${ }^{2}$ STIKES Santo Borromeous, ${ }^{3}$ Poltekkes Kemenkes \\ Bandung \\ Email:mamat_lukman@yahoo.com
}

Submitted: 13-02-2018 Accepted: 07-08-2018 Published: 10-8-2018

\begin{abstract}
Death is something definite. Awareness about the certainty of the coming death raises different responses depending on each person, including the elderly. Differences in social background, beliefs, and life experiences have shaped their respective levels of spirituality elderly, but the elderly still be experiencing anxiety to face the death. Not infrequently the death anxiety felt excessively, causing symptoms that can be observed.This study aimed to analyze the factors associated with death anxiety in elderly Batak tribe who live in Bandung, which includes the quality of life, life satisfaction, and culture. The study employed a descriptive correlational design, particularly cross-sectional design. There were 98 elderly who served as participants. The samples were chosen by using accidental sampling methods and criteria for inclusion. The data were analyzed by using Chi-square and binary logistic regression. The results showed that there was correlation between life satisfaction, and culture with death anxiety in elderly Batak tribe who live in Bandung (the two of factors has $p$ value $<0.001$ each) and with the binary logistic regression analysis of the factors known that the satisfaction of life is the most dominant factor that associated with death anxiety with OR value of 0.122 . Community nurses need to pay attention to the improvement of satisfaction of life of the elderly. High satisfaction of life of elderly people have an impact on reducing the risk of death anxiety in elderly people, without forgetting other factors.
\end{abstract}

Keywords: Culture, death anxiety, elderly, life satisfaction, quality of life. 
Mamat Lukman: Factors Associated with Death Anxiety in Elderly Batak Tribe Who Live in Bandung

\section{Introduction}

Aging was a process that which is natural to be facing by human. In this process, the most crucial stage is the stage of getting old. A dividing line between the ages of adult and elderly is usually the age of 60 years (Santrock, 2004). At this stage, the elderly experience decreasing in physical condition, psychologically and socially that is mutually interact with each other. These conditions are the causes of the various problems in the elderly and others who live with them. For some people, age tend accompanied by the growing awareness of impending death and this awareness led to some people consider the arrival of death is the same as the arrival of a friend (Litot, 2010).

Death is something that is certain, which in turn all people would agree and accept the fact that death is the end of the implementation of the development tasks. Lack of awareness about the certainty of the coming death raises different responses depending on each person. Differences in social background, beliefs, and life experiences have shaped their respective levels of spirituality elderly, but the elderly still be experiencing anxiety will face death. Not infrequently the death anxiety felt excessively, causing symptoms that can be observed from the outside.

Carpenito-Moyet (2008) mentioned the death anxiety as a condition in which individuals experience feelings of anxiety because of the discomfort that is not clear or vague or fear generated by the perception of a threat to the existence of a person, whether real or imagination. Death anxiety can be related to the arrival of death itself, how to die, and pain or suffering that may accompany the arrival of death (Abdel-Khalek, 2005). These conditions may interfere with the development tasks that must be passed by an elderly, one of which is to prepare his own death (Monks, 2009).

Experts of gerontology revealed that the elderly actually have a high probability of experiencing anxiety disorders caused by certain factors (Santrock, 2004). Smith, Ingram, and Brighton (2009) mentioned that the anxiety of death in the elderly is influenced by the quality of life and satisfaction of life. While Lehto and Stein (2009) also mentioned that culture is also an influencing factor. Lehto and Stein stated that death anxiety is also formed and can vary by culture adopted by someone. Greenberg et al. which sparked Terror Management Theory (TNT) states that people also use culture as death anxiety reducer.

Based on review of literature on death anxiety in the elderly, not many was found that relate death anxiety to quality of life, life satisfaction, especially with the culture. Research related to culture and death anxiety is still very little, while Lehto and Stein (2009) states that death anxiety is also formed and can vary by culture adopted person. Culture affects variation in how one views the death and about what happens when someone dies. The focus of the research to be conducted by the researcher himself is the anxiety of death in elderly Batak tribe. Interestingly, the characteristics of the Batak tribe, migrated as far as any kind, at least have a strong desire to: (1) Pass away with certain conditions which are no longer mourned his death with great weeping and sorrow, but celebrated as a party or event joy, (2) Want his body was taken to his hometown in Tapanuli (North of Sumatera) to be buried there, near the tomb of grandparents, parents, and siblings (mulak tu bonapasogit = return home; living or dead).

It is predicted that the Batak culture can potentially lead to an increase in death anxiety in the Batak people, particularly the elderly. Elderly Batak are eager to die in a state of saurmatua (the term for died in old age, the highest levels of death in Batak culture, and ceremonies for this death is a party) and also greatly longed to be buried in his native land. Term saurmatua itself apart elderly also includes hagabeon (successfully reproduce), hasangapon (honor), and hamoraon (wealth). Death anxiety can occur especially due to the issues of reproduce, honor, and wealth that not necessarily be owned by every elderly of Batak.

An interesting phenomenon, the Batak tribe of death is the present of turmoil as an expression of death anxiety related to levels of death in the Batak culture. Researcher tried to get information out of 4 elderly couples of Batak tribe that researcher met in Bandung with the age of 61-69 years, on 16 and 17 July 2014. When the discussions 
Mamat Lukman: Factors Associated with Death Anxiety in Elderly Batak Tribe Who Live in Bandung

concerning the death, it was revealed that it is a burden on the mind as well as for their own grief of knowing that if dies excluding levels or categories saurmatua death. Further excavations in mind there are times when the elderly to experience feelings of anxiety, it is difficult to sleep, and irritability associated with thinking that if death is not saurmatua elderly.

Based on the phenomena above and the results of interviews with four elderly couples and an elderly widow Batak tribe raises the curiosity of researchers to see "Factors associated with death anxiety in Batak tribe elderly who live in Bandung". Referring to Simanjuntak (2006) which states that basically migration Batak people out of the land of his birth with the same reason, namely to obtain hagabeon (successfully reproduce), hasangapon (honor), and hamoraon (wealth). Characteristics of Batak migrants equally among others accepted to the culture, forming clan associations, and how much was migrated and urban life was affected, but still makes hometown as the best protection. These things became researcher considerations to choose the respondents who live in Bandung. The aim of this study was to know the factors that deals with anxiety of deaths in the tribe of batak seniors living in bandung .

\section{Method}

The type of research used is quantitative research with the design of descriptive of correlational with the approach of crosssectional which aimed to know the factors associated with death anxiety of the elderly in the tribe of Batak living in Bandung. That means that researcher looking for the relation between independent variables (factors) with dependent variable (death anxiety). The population in this study were elderly in Batak tribe who live in Bandung whose numbers are certainly unknown. Determining of sample size used the formula of Lemeshow for the population is unknown (infinite), so that the sample was 96 elderly of Batak.

The instrument for measuring the degree of death anxiety use Death Anxiety Scale; Questionnaire of Batak culture is designed to measure the elderly appreciation of culture. This questionnaire has been checked and approved for use in this study by DR. Herman Nainggolan, an anthropologist who specializes Batak culture and taught at several universities in North Sumatra. The questionnaire contains 34 questions. Questionnaire World Health Organization Quality of Life (WHOQOL) was used to measure the quality of life (Milosevic et al., 2012 and Silva et al. 2014). The satisfaction of life for the elderly was measured using the Scale With Life Satisfaction (SWLS) developed by Diener et al. and was published in 1985.

In this study used Chi-square test, because the variables to be studied in the form of categorical.

In the field of health to determine the degree of relationship used measure of relative risk (RR) and Odds Ratio (OR). OR size used in the design of case-control and cross-sectional. In this research also used a binary logistic regression test to find out which factors most associated with the anxiety of death of elderly Batak who lived in Bandung.

\section{Result}

Table 1 Chi-Square Results

\begin{tabular}{|c|c|c|c|}
\hline No & Variable & P Value & OR \\
\hline 1 & $\begin{array}{l}\text { Correlation between 1st domain quality of life ( physical ) with death } \\
\text { anxiety }\end{array}$ & 0.928 & 0.959 \\
\hline 2 & $\begin{array}{l}\text { Correlation between domain 2nd quality of life (psychology ) with } \\
\text { death anxiety }\end{array}$ & 0.106 & 2.105 \\
\hline 3 & $\begin{array}{c}\text { Correlation between 3rd domain quality of life (social) with death } \\
\text { anxiety }\end{array}$ & 0.553 & 1.305 \\
\hline 4 & $\begin{array}{c}\text { Correlation between 4th domain quality of life (environment) with } \\
\text { death anxiety }\end{array}$ & 0.706 & 1.179 \\
\hline
\end{tabular}


Mamat Lukman: Factors Associated with Death Anxiety in Elderly Batak Tribe Who Live in Bandung

\begin{tabular}{lccc}
\hline 5 & Correlation between satisfaction of life with death anxiety & $<0.001$ & 9.9 \\
6 & Correlation between culture with death anxiety & $<0.001$ & 19.25 \\
\hline
\end{tabular}

Table 2 The First Modeling of Binary Logistic Regression

\begin{tabular}{lccccc}
\hline & Wald & Sig. & Exp(B) & \multicolumn{2}{c}{ 95\% C.I.for EXP(B) } \\
\hline $\begin{array}{l}\text { QOL 2nd } \\
\text { domain }\end{array}$ & .419 & & & Lower & Upper \\
\hline Life Satisfaction & 8.861 & .517 & 1.406 & .501 & 3.940 \\
\hline Culture & 5.377 & .003 & .133 & .035 & .503 \\
\hline Constant & 5.653 & .020 & .070 & .007 & .662 \\
\hline
\end{tabular}

Table 3 The Final Modeling of Binary Logistic Regression

\begin{tabular}{lccccc}
\hline & Wald & Sig. & $\operatorname{Exp(B)}$ & \multicolumn{2}{c}{ 95\% C.I.for EXP(B) } \\
\hline Life Satisfaction & 10.116 & .001 & .122 & Lower & Upper \\
Culture & 5.365 & .021 & .071 & .033 & .445 \\
Constant & 7.400 & .007 & 29.624 & .008 & .666 \\
\hline
\end{tabular}

More than half of respondents $(67.4 \%)$ having a bad quality of life in physical. More than half of respondents $(59.2 \%)$ having a bad quality of life in psychological. More than half of respondents $(60.2 \%)$ having a good quality of life in social. More than half of respondents $(52 \%)$ having a bad quality of life in the domain of environment. Most of Batak tribe elderly $(83.7 \%)$ who live in Bandung. Almost all (91.8\%) elderly Batak tribe who live in Bandung still appreciate the culture, although it is known almost half have 40-50 years living overseas. More than half $(68.4 \%)$ elderly Batak tribe who live in Bandung has a low death anxiety.

Chi square test was obtained value of $p$ $<0.001$, it can be concluded that there is a strong relationship between the culture of the anxiety of death in elderly respondents Batak tribe who live in Bandung. Value OR $=19.25$ means that respondents with a high cultural appreciation of 19 times likely to experience higher death anxiety than respondents with low cultural appreciation.

The test was used logistic regression enter method in which there were several stages before the final model obtained. The first step is to see the results of bivariate analysis, the study variables are incorporated into the logistic regression is a variable that has a value of $p<0.25$. Based on the results of the bivariate analysis it is known that the value of $p<0.25$ was on quality of life (domain 2 psychology), life satisfaction, and culture. Thus it can be continued for a multivariate analysis on these three variables.

Based on multivariate modeling that has been done, from the initial model unknown variables that contribute to the level of anxiety elderly Batak tribe who live in Bandung is the life satisfaction and culture with $\mathrm{p}$ value $<0.05$.

Multivariate modeling is done by issuing a variable $p$ by one of its greatest value to all its $\mathrm{p}$ value $<0.05$. The next stage is to modeling after removing the second domain of life quality due to $p>0.05$. modeling is done by issuing a variable $p$ by one of its greatest value to all its $p$ value $<0.05$. The next stage is to modeling after removing the second domain of life quality due to $\mathrm{p}>0.05$.

Exp (B) obtained showed that the variables most associated with the level of death anxiety in elderly Batak tribe who live in Bandung is living Satisfaction with Exp (B) or $\mathrm{OR}=0.122$.

Based on the above tables can be summarized as follows:

(1) Life satisfaction $(\mathrm{OR}=\mathbf{0 . 1 2 2})$

The results obtained odds ratio analysis of life 
satisfaction variable is 0.122 means elderly Batak tribe who live in Bandung who has a low life satisfaction 0.122 times higher risk for experiencing high death anxiety compared to elderly who have high life satisfaction.

\section{(2) Culture $(\mathrm{OR}=\mathbf{0 . 0 8 8})$}

The results obtained odds ratio analysis of cultural variables is 0.088 means that elderly Batak tribe who live in Bandung with a high cultural appreciation 0.088 times higher risk for experiencing high death anxiety compared to elderly with low cultural appreciation.

(3) To determine which variables most associated with the dependent variable, we can determine from the OR of the significant variables, the greater the value of OR means greater relationship to the dependent variable. Table 3 shown that variable life satisfaction has a higher OR, so this variable was the most associated with death anxiety.

\section{Discussion}

In this study there was no significant association between quality of life (which represent each of the domains of physical, psychological, social, and environmental) and the anxiety of death in the elderly. Physical domain in terms of aspects of physical health more than half are experiencing poor quality of life, but the possibility of elderly sees this as a fairness condition because more than half of the respondents aged 70 years and over. Acoording to psychological domain more than half of the respondents experienced a poor quality of life. It is also supported by the data that more than half of the respondents aged 70 years and over, plus the respondents said that has not been entirely of children they had been married.; This is usually a separate psychological burden for the elderly Batak.

In Social domain more than half of the elderly Batak tribe has a good quality of life. This condition is supported by the data that up to the time of collection mostly elderly still have a spouse (husband or wife). In addition, all respondents are still involved in social activities, especially in the elderly and in the container section Batak community activities (customs), but this condition was apparently not related to death anxiety they experience. Domain environment in terms of: freedom, physical safety and security, home environment, financial resources, health and social care, the opportunity to acquire new skills and information, participation and opportunities for recreation, activity in the environment, and transportation. More than half of the elderly experience poor quality of life. The poor quality of life can be affected environment (Suryani, 2014) that advanced age (more than half have been aged 70 years and over) so it had limitations in terms of freedom, physical safety and security, as well as transport, but the results of the analysis also did not have a significant association with death anxiety they experienced.

From the results of this study, we can see that there was was a significant relationship between life satisfaction with the death anxiety in the elderly. This results is corresponds to some research on the relationship between life satisfaction and death anxiety. Research results of Abdel-Khalek and Al-Sabwah (2005) in Egypt showed the relationship between life satisfaction scores with scores on Death Anxiety Scale (DAS). Similarly, the results of research Roshani (2012) showed that there is a significant relationship between life satisfaction and death anxiety correlation coefficient $-0.262(\mathrm{P}<0.004)$. In other words, there is a significant negative correlation between life satisfaction and death anxiety so that the increase in life satisfaction, death anxiety decreased.

The results showed that most of Batak tribe elderly who live in Bandung still has high appreciation of Batak culture. The Batak people usually remain bound by customary culture wherever they are, even in the seacoast area. High appreciation of the value of culture is also a reflection of one's cultural identity, including the elderly Batak tribe. Therefore, not surprisingly, the elderly of Batak tribe despite living overseas remained true to its culture.

The results of this study show that people are in overseas Batak although still adhere to traditional culture, including the death that does have a cultural dimension from the standpoint of Batak tribe. High appreciation of the Batak culture proven to give effect to the anxiety of death in the Batak tribe elderly who longed to experience the death of an ideal. 
Mamat Lukman: Factors Associated with Death Anxiety in Elderly Batak Tribe Who Live in Bandung

Unlike the finding in this study, Lehto' study found that more than half of the elderly experiencing a high death anxiety. The high death anxiety among the elderly is closely related to the decline in physical and psychological problems (Lehto, 2009). High death anxiety can be caused by what is happening in the lives of individuals. Grossberg (2001) mentioned that the event may be associated with loss events that suddenly, for example, pensions and financial problems, the illness or death of a loved one; decline in physical, cognitive, or emotional health of the elderly.

Multivariate analysis showed that life satisfaction and cultural factors significantly associated with death anxiety in Batak tribe elderly who live in Bandung, but statistically life satisfaction factor was the most closely correlated. . The results of this analysis did not fully comply with Smith, Ingram, and Brighton (2009) which stated that the death anxiety in the elderly is influenced by the quality of life and life satisfaction of the elderly. However, Lehto and Stein (2009) mentioned that cultural factors play a role in influencing the level of death anxiety of elderly.

\section{Conclusion}

The results showed that there was no significant correlation between the quality of life as measured by the WHOQOL-BREF with the anxiety of death in elderly Batak tribe who live in Bandung. WHO itself mean quality of life consists of domains that include the physical domain, psychological domain, social domain, and environmental domains.

When someone entered the phase of elderly, they will undergo changes, whether physical, psychological, social, and environmental. These changes can affect the quality of life of the elderly. Quality of life when viewed from the physical health dimension is the evaluation of acceptance and happiness will be aspects of physical health as the absence of pain and discomfort due to illness, wellness and energy, sleep quality, and free from drug addiction. Thus, more satisfied person's physical health aspects, the higher the quality of life.
The conclusion showed that most of Batak tribe elderly who lived in Bandung has high life satisfaction. Life satisfaction is one's ability to enjoy the experiences with the full significance. Life satisfaction can be achieved by having a decent income, good health and an active lifestyle in the family and friendship. Life satisfaction arising from fulfilling the needs or expectations and are the cause or the means to enjoy. Elderly who can accept themselves and the environment in a positive way will be satisfied with his life.

\section{References}

Abdel-Khalek, A.M. (2005). Death anxiety in clinical and non-clinical groups. Death Studies Journal, 29(3).

Carpenito \& Moyet. (2008). Nursing diagnosis: Application to clinical practice. Philadelphia: Lippincott Williams \& Wilkins.

Grossberg. (2001). Generalized anxiety disorder in the elderly. Psychiatric Clinics of North America, 24(1).

Lehto, R.H., \& Stein, K.F. (2009). Death anxiety: An analysis of an evolving concept. Research and Theory for Nursing Practice. An International Journal, 23(1).

Litot, Ed. (2010). When death comes as a friend. USA: AuthorHouse.

Milosevic et al. (2012). Predictors of lower work ability among emergency medicine employees: The croatian experience. Emergency Medical Journalemermed-2011-200780.

Monks, F.J., et al. (2009). Psikologi perkembangan. Yogyakarta: Gadjah Mada University Press.

Roshani, K. (2012). Relationship between religious beliefs and life satisfaction with death anxiety in the elderly. Annals of Biological Research, 3(9), 4400-4405.

Santrock, J.W. (2004). A topical approach to 
Mamat Lukman: Factors Associated with Death Anxiety in Elderly Batak Tribe Who Live in Bandung

life-span development. New York: McGrawHill.

Silva, et al. (2014). Cut-off point for WHOQOL-brief as a measure of quality of life of older adults. Journal Rev Saude Publica, 48(3), 390-397.

Simanjuntak, B.A. (2006). Struktur sosial dan sistem politik Batak Toba hingga 1945: Suatu pendekatan sejarah, antropologi budaya politik. Jakarta: Yayasan Obor Indonesia.

Smith, M., et al. (2009). Detection and assessment of late-life anxiety. Journal of Gerontological Nursing, 35.

SKp, S. (2014). Quality of Live of People with Mental Illness. Abstrak. 